\title{
NUMERICAL CONTROL OF MACHINING PARTS FROM ALUMINUM ALLOYS WITH STICKING MINIMIZATION
}

\author{
Volodymyr Kombarov'1, Volodymyr Sorokin ${ }^{1}$,Yevgen Tsegelnyk ${ }^{2}$, Sergiy Plankovskyy², Yevhen Aksonov², Olena Fojtů ${ }^{3}$ \\ ${ }^{1}$ National Aerospace University "Kharkiv Aviation Institute", Kharkiv, Ukraine \\ 2O.M. Beketov National University of Urban Economy in Kharkiv, Kharkiv, Ukraine \\ ${ }^{3}$ Czech Technical University in Prague, Prague, Czech Republic \\ Email: y.tsegelnyk@gmail.com
}

\begin{abstract}
To implement a lot of technological processes in the manufacturing of aircraft parts from aluminum alloys, it is necessary to move the tool at a high speed. High requirements for accuracy and manufacturing quality aircraft parts are provided with application of CNC systems with adaptive control algorithms, in which due the mutual influence of the process parameters provided by the parameters of quality and accuracy. Among a number of factors adversely affecting the quality of high speed machining of aluminum alloys in the paper questions influence Lookahead system distortion predetermined (set up) cutting parameters on the formation conditions of the sticking material to the tool. The paper deals with high-speed machining without the use of a cooling lubricant (coolant). The paper provides a qualitative description of the heat generation variation in the cutting zone. It is concluded that it is necessary to cutting speed variation when feed variating. An experimental investigation of the cutting parameters for the appearance of the effect of the processed material sticking on the tool for alloy 1933 has been carried out. Areas of an unfavorable (negative) combination of parameters leading to the sticking of the material to the tool have been identified. The method of cutting modes adaptation to contour feed rate variation on curvilinear areas of a processing trajectory is proposed. The analysis of variation in cutting parameters with the partial deceleration of the spindle simultaneously with the deceleration of feed when moving along the path is carried out. The possibility of excluding the sticking of the processed material to the tool when variation the rotation speed by $20 \ldots 30 \%$ is shown. The proposed method is implemented in the CNC system and used for manufacturing of "Antonov" company airplane parts.
\end{abstract}

Keywords: High-speed Machining, Adaptive Control, CNC System, Look-ahead Algorithm, Feed, Cutting Process, Sticking.

\section{Introduction}

Quite a number of technological processes are implemented at high processing speeds, e.g. highspeed milling [1, 2], laser welding [3], laser cutting $[4,5]$, hybrid additive and subtractive machining [6, 7], etc. The conduct of these processes is characterized by complex multi-parameter connection between the technological process and the obtained indicators of quality and accuracy [8]. To ensure these indicators, CNC with adaptive control algorithms are used.

The aim of the adaptive control system is the automatic maintenance of any processing parameters in a predetermined range of deviation in the conditions of various influencing factors on process. It is obvious that the greatest influence on the result provides direct cutting process itself. This process has been investigated extensively by various authors [9-12].
One of the unfavorable phenomena during cutting is sticking material to the tool, which occurs as a result of an unfavorable combination of process parameters [13]. The causes of such combinations may be errors in assignment process parameters and functioning features of CNC equipment.

Using Look-ahead algorithms provides the necessary for high-speed machining accuracy [14, 15]. On the other hand, feed reduction in some areas leads to a considerable reduction in the supply amount of the tooth, which under specific conditions leads to disruption of the normal cutting process. Furthermore, it should also take into account the dynamics of the electric motor control [16-18] in order to avoid processing mode deviation.

In this paper we consider the problem to ensure stable cutting and elimination of surface defects, resulting in sticking of the material on the tool. The problem of developing a new method for cutting speed adaptive control in the mode of contour feed tracking is considered. 


\section{Review of Machining Adaptive Control Methods}

The basic idea of using adaptive control systems is to provide a response to deviations in processing parameters in order to correct or completely eliminate them to ensure the required accuracy and quality of treatment [19]. Machines adaptive control systems are realized as PC-based with the developed programmable possibilities. Enhanced functionality and adaptive capabilities of the CNC systems are achieved due to their improvement by increasing the software that implements the adaptation algorithms [19]. Adaptation methods and algorithms depend on the types of technological operations realized on the equipment.

In CNC systems for turning there are functions to maintain a constant cutting speed G96, G97 [20, 21]. In the mode of maintaining a constant cutting speed, the CNC system variation the spindle rotation speed depending on the positioning of the cutter along the axis, which possible to process the diametrical size of the part (Fig. 1). This mode is used to stabilize the cutting process and obtain the same surface quality in areas with different diameters.

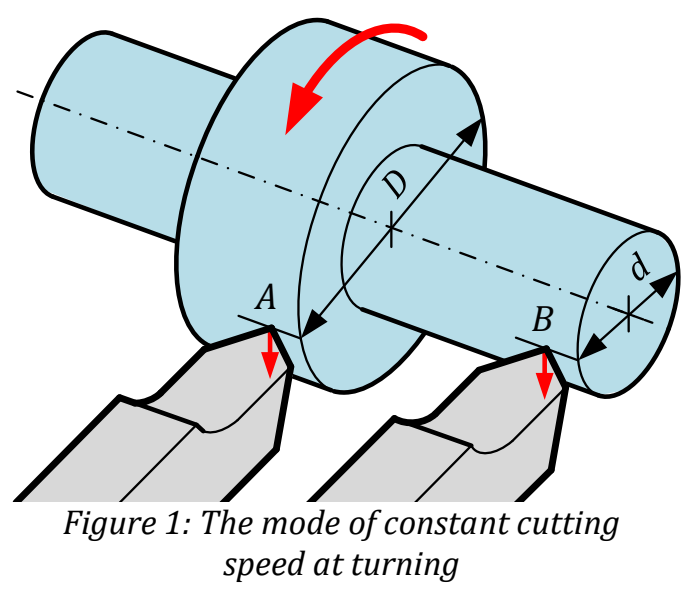

For milling equipment, the most often considered the problem of adapting the feed to maintain a constant cutting force [22] or the torque of the spindle [23]. In most CNC systems, in adaptive feed control mode for internal use, the CNC sets the spindle speed potentiometer to $100 \%$ and no spindle speed adjustments are allowed. In this mode, the operator cannot change the spindle speed. The CNC system takes over the function of the feed potentiometer variation (Fig. 2). In this mode, the variation in the speed of movement along the processing path is determined by the amount of load on the spindle, which provides an increase in productivity.



Figure 2: Feed adaptation according to the load on the spindle

The contour feed adaptation can be carried out not only according to the spindle load but also according to the path shape. In the machining CNC systems with tool diameter correction, the functions G64, G65 [24] maintain a constant contour feed at the point of contact of the tool, provide a constant feed to the tooth when machining curved concave or convex sections of the machining path (Fig. 3). Similar functions are available in various CNC systems [25].
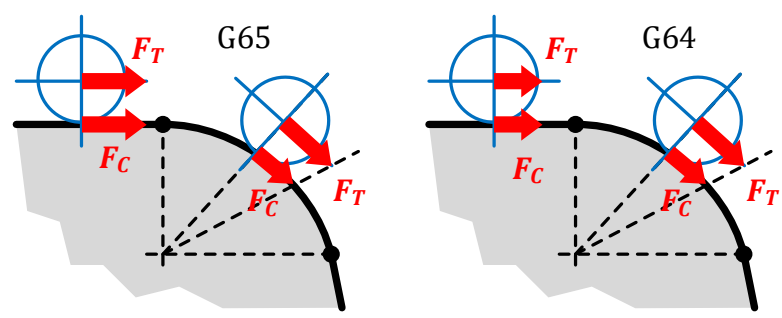

Figure 3: Maintaining constant feed per tooth: $F_{T}$-feed specified for the tool center; $F_{C}$-feed specified for the point of the cutter contact

The Look-ahead CNC subsystem allows a rational plan for the contour feed variation along the machining path, however, in real machining, the diagram of the contour feed variation is usually different from the previously generated plan. Feed variation should be performed in the following situations:

- when the processing operational mode variation by setting the percentage of feed (\% F) and spindle speed corrector $(\% \mathrm{~S})$;

- while ensuring the limits of the machine axial characteristics are not exceeded, for example, exceeding the maximum permissible axial feed during the execution of the control program at an increased percentage of feed;

- with an adaptive response to limit states of adjacent units, for example, feed reduction when the spindle load is exceeded. 
In such situations, the contour feed control system adjusts the existing feed plan variation in accordance with the factors that arise during the processing. Which leads to a deviation from the programmed combination of processing parameters.

The use of S-shaped algorithms of acceleration/deceleration in the Look-ahead system ensures smooth variation in the contour feed [2628], which positively affects the accuracy of movement along the path, but significantly complicates the provision of processing technological modes. A feed decrease in specific sections of the path leads to a significant decrease in the amount of feed per tooth, under specific conditions it can lead to disruption of the normal cutting process.

During cutting, thermal phenomena determine the temperature in the cutting zone, which has a direct effect on the nature of plastic deformation during the formation of chips, sticking, chip shrinkage, and affects the cutting forces and microstructure of the surface layer (Fig. 4) [29, 30].
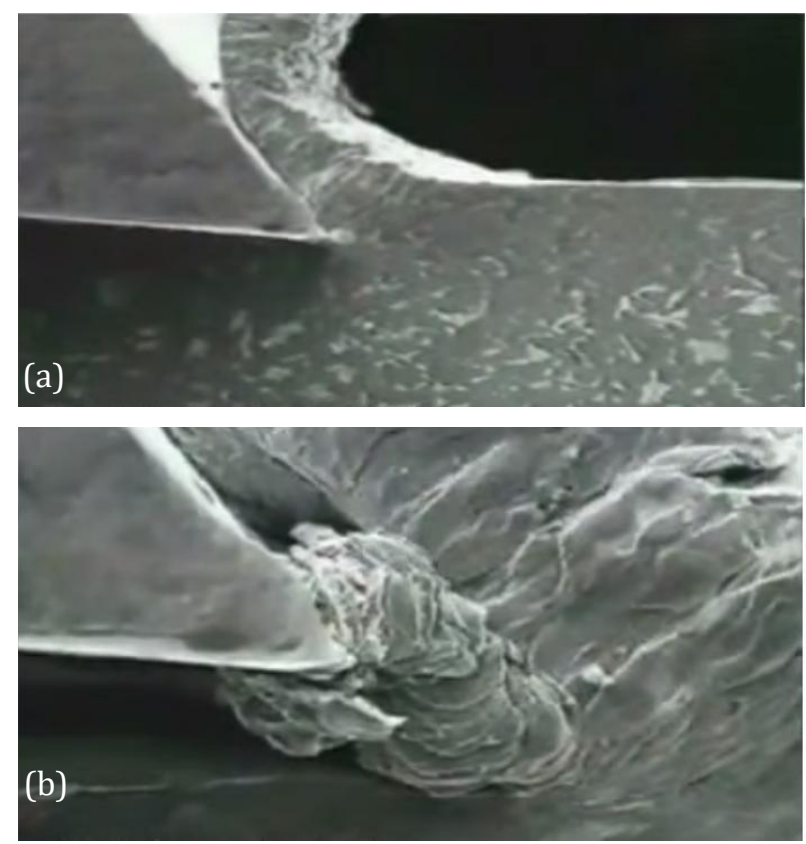

Figure 4: Cutting process: (a) - normal cutting process; (b) - cutting with sticking (material sticking to the tool) [30]

For a particular processed metal and constant lubrication conditions, the size and shape of the sticking are determined only by the temperature at the front face of the tool blade. The cutting speed, the thickness of the cut layer and the rake angle are influenced insofar as they affect the cutting temperature [30].

The heat generated during the cutting process is transferred to the chips $\left(Q_{C H}\right)$, to the workpiece ( $Q_{W}$ ), to the tool ( $Q_{T}$ ), and to the environment by radiation $\left(Q_{R}\right)[31]$.

$$
Q=Q_{C H}+Q_{W}+Q_{T}+Q_{R}
$$

With increasing cutting speeds, most of the heat is removed by the chips [30]. Normal chip formation is required to remove heat from the cutting zone during high-speed machining. For this reason, feed deceleration when machining kinked or curved path sections due to reduced chip volume can lead to undesirable temperature rise and sticking.

The amount of heat released during the cutting process can be estimated by the expression [30]:

$$
Q=p_{c} \cdot F_{c} \cdot V_{c}
$$

where $p_{c}$ is the specific cutting pressure; $F_{c}$ is the cross-sectional area of the cut material layer; $V_{c}$ is the cutting speed.

With an increase in $V_{c}$, the cutting power increases and, therefore, the power of the heat sources. However, this dependence is not directly proportional, since, with an increase in $V_{c}$, the $p_{c}$, $F_{c}$ components decreases due to a variation in chip shrinkage. In addition, the part of the heat that passes into the tool decreases due to a decrease in the length of the contact area, that is, most of the heat disappears with the chips, so the growth of $Q$ from $V_{c}$ further slows down [30].

Investigation of the aluminum alloys AMg6, 01570C, B1469 cutting showed that expression (2) corresponds to the experimental data up to cutting speeds of the order of $700 \mathrm{~m} / \mathrm{min}$ [32], and by a 10fold variation in the feed per tooth, the heat released during cutting changes by a factor of 5 . Consequently, a decrease in feed at a constant cutting speed leads to an increase in chip temperature.

During the movement of the machining path with feed deceleration, it is not possible to influence the values of $p_{c}, F_{c}$.

When moving along the trajectory of processing with a slow feed there is no way to affect the values $p_{c}, F_{c}$. Obviously, in order to influence the heat generation in the cutting zone (2) in such areas, it is possible to variation of the cutting speed $V_{c}$ value.

The effect of the material sticking to the tool is observed when processing viscous materials in some cutting conditions (Fig. 4, b). A temperature increase in the cutting zone creates the conditions for the appearance of this effect. The sticking is categorically unacceptable to the machining of aircraft parts. Traditionally, this problem is solved by changing the design of the cutting tool or using coolant, but this paper deals with machining without the use of coolant. Adaptation of the cutting speed in accordance with the variation of feedrate is not considered in the works of other authors and implementations of CNC systems. 


\section{Investigation of high-Speed Machining Limiting Modes for Aluminum Alloys}

The investigation of the influence of cutting parameters on the machining of 1933 alloy was carried out by the method of a control sample test milling. The investigation was carried out with the provision of constant processing parameters such as cutting speed, cutting width, the thickness of the cut layer, and feed per tooth. Acceleration/ deceleration to a given technological feed was carried out outside the processed workpiece (Fig. 5).

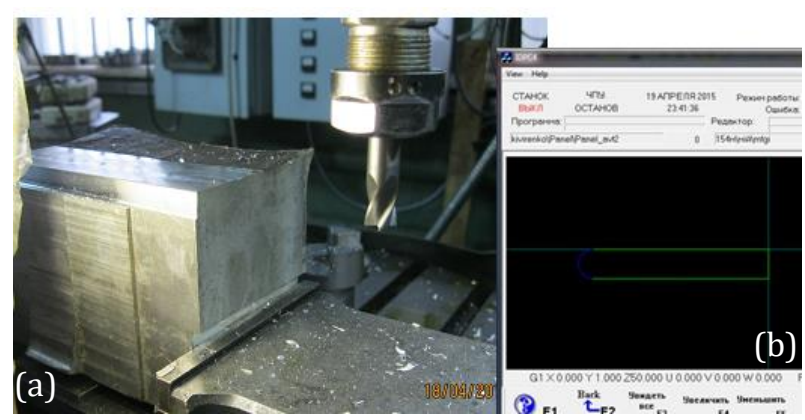

Figure 5: Investigation of limiting modes: (a) machining of the workpiece; (b) - machining path

For each investigated combination of parameters of cutting speed, width, and depth of cutting, Table 1 was filled in with marks on the presence of material sticking to the tool. As a result of the investigation, a stable regularity of the appearance of the corresponding phenomenon in the middle range of feeds was revealed. In Fig. 6 shown the state of the tool after control sample machining with a constant cutting speed at various feeds. As can be seen from the given material, in a particular experiment, sticking is absent at feeds less than $100 \mathrm{~mm} / \mathrm{min}$ and feeds of more than $1000 \mathrm{~mm} / \mathrm{min}$.

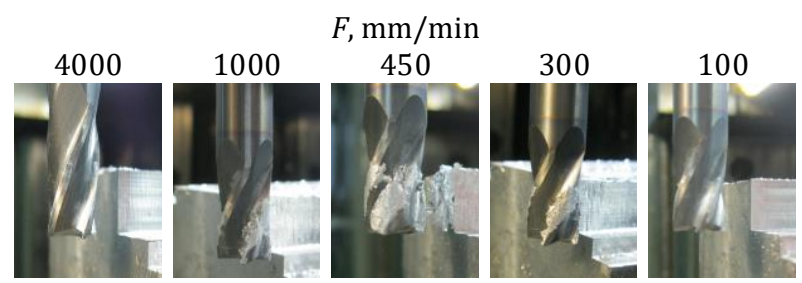

Figure 6: State of the tool after the control sample machining

A range of cutting speeds and corresponding feeds were found, at which the material sticking to the tool (Fig. 7). For each cutting speed, there is a range of problematic combinations of cutting parameters, which leads to the sticking of material to the tool. As the cutting speed increases, the area of the problematic combination increases. With a decrease in the cutting speed in accordance with the area of the problematic combination of parameters decreases, while the upper limit moves in the direction of decreasing feed, and the lower one - in the direction of its increase. With a decrease in the cutting speed below $940 \mathrm{~m} / \mathrm{min}$, the effect of material sticking to the tool was not observed in the experiments performed.

Table 1. Modes of investigation

\begin{tabular}{|c|c|c|c|c|c|c|c|c|c|}
\hline $\begin{array}{c}F, \\
\mathrm{~mm} / \mathrm{min}\end{array}$ & 온 & $\stackrel{\circ}{\circ}$ & 요 & $\stackrel{\text { ○ }}{\text { ○े }}$ & 농 & ஓ & ஓ & ○ & $\stackrel{\text { O }}{\stackrel{N}{N}}$ \\
\hline$f_{z}, \mathrm{~mm}$ & $\begin{array}{l}\text { 농 } \\
\text { ᄋ } \\
\text { ᄋ } \\
0\end{array}$ & 용 & $\begin{array}{l}\stackrel{1}{\Im} \\
\text { ᄋ } \\
0 \\
0\end{array}$ & $\begin{array}{l}\text { 구 } \\
0 \\
0 \\
0\end{array}$ & 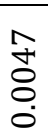 & $\begin{array}{l}\text { ஜூ } \\
\text { ○ } \\
\circ \\
0\end{array}$ & $\begin{array}{l}\text { ஜ } \\
\infty \\
0 \\
0 \\
0\end{array}$ & $\begin{array}{l}\stackrel{+}{0} \\
\stackrel{-}{0} \\
0\end{array}$ & $\begin{array}{l}\infty \\
\stackrel{0}{0} \\
\stackrel{0}{0} \\
\stackrel{0}{0}\end{array}$ \\
\hline $\begin{array}{c}V_{C} \\
\mathrm{~m} / \mathrm{min}\end{array}$ & \multicolumn{9}{|c|}{1500} \\
\hline$a_{p}, \mathrm{~mm}$ & \multicolumn{9}{|c|}{12} \\
\hline$a_{e}, \mathrm{~mm}$ & \multicolumn{9}{|c|}{2} \\
\hline Result & - & + & + & + & + & + & + & + & - \\
\hline
\end{tabular}

where $a_{p}$ is the axial depth of cut, mm; $a_{e}$ is the radial depth of cut, $\mathrm{mm}$; + is the process with sticking to the tool; - is a process with no sticking to the tool.

A range of cutting speeds and corresponding feeds were found, at which the material sticking to the tool (Fig. 7). For each cutting speed, there is a range of problematic combinations of cutting parameters, which leads to the sticking of material to the tool. As the cutting speed increases, the area of the problematic combination increases. With a decrease in the cutting speed in accordance with the area of the problematic combination of parameters decreases, while the upper limit moves in the direction of decreasing feed, and the lower one - in the direction of its increase. With a decrease in the cutting speed below $940 \mathrm{~m} / \mathrm{min}$, the effect of material sticking to the tool was not observed in the experiments performed.

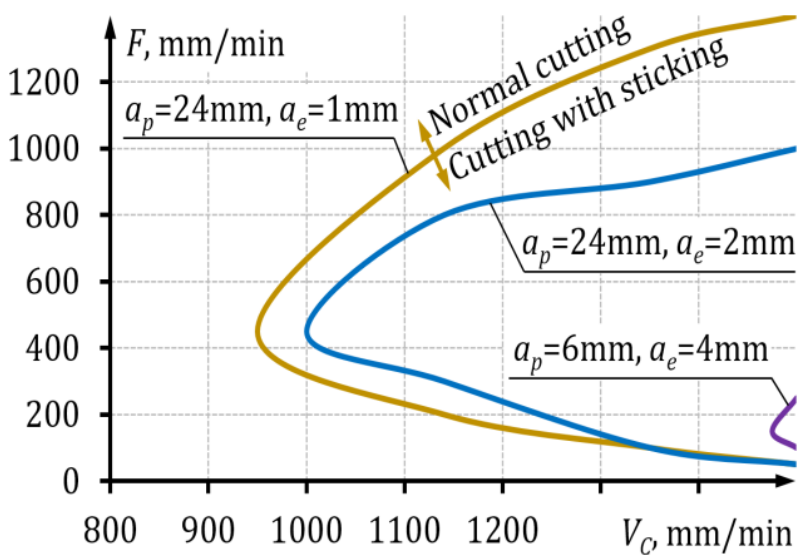

Figure 7: Areas of unfavorable combination of cutting parameters

To determine the average temperature of the processing zone, the cutting zone was thermographed during test milling. Thermography results for one of the modes are shown in Fig. 8. 


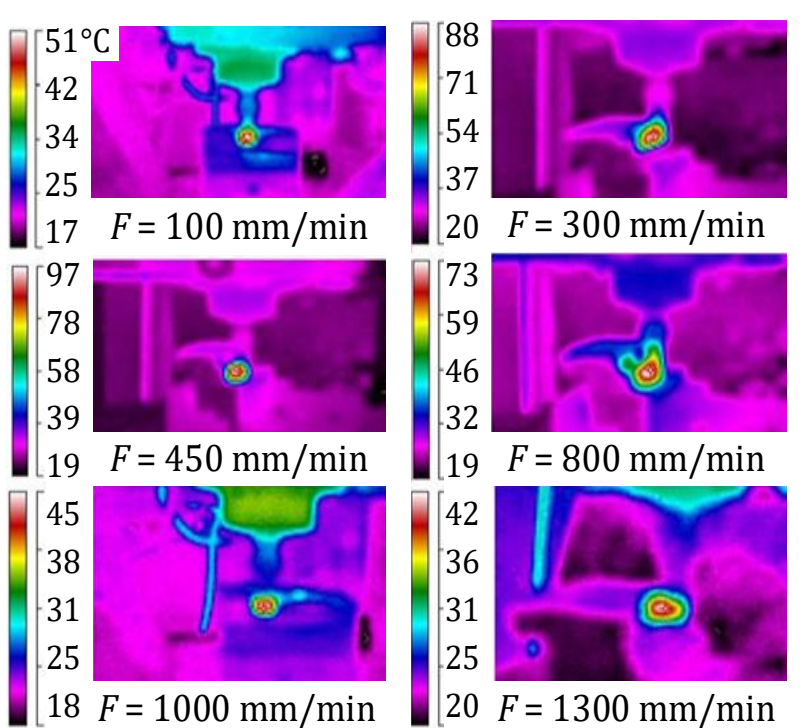

Figure 8: Monitoring the temperature in the cutting zone

In Fig. 9 shown the graphs of variation in the observed temperature in the cutting zone. From the graphs, it is clear that material sticking to the tool occurs when a specific temperature value is exceeded and is observed in the cutting zone. The boundary of the area of the cutting parameters unfavorable ratio correlates quite well with the limit of exceeding the limiting temperature.

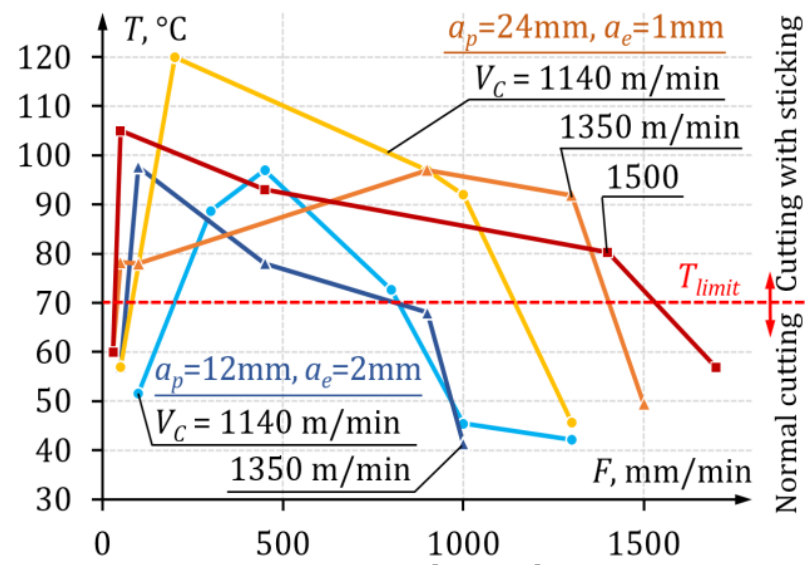

Figure 9: Variation in observed temperature in the cutting zone

Thus, the investigations carried out made it possible to determine for a specific material (alloy 1933) unfavorable ratios of cutting parameters (Fig. 7) at which the workpiece material sticking to the tool. The analysis of the observed temperature in the cutting zone confirmed the generally accepted opinion that it is precisely the excess of a specific temperature state in the cutting zone that leads to the sticking of the material to the tool.

To eliminate this effect, a method for adaptive control of the cutting speed following a variation in contour feed is proposed.

\section{Adaptation of Cutting Modes to Contour feed Rate Variation on Curvilinear Areas of a Processing Trajectory}

The operation of the method will be demonstrated by the example of machining the structural element of the stringer belt in the area in wall thickness variation (Fig. 10).

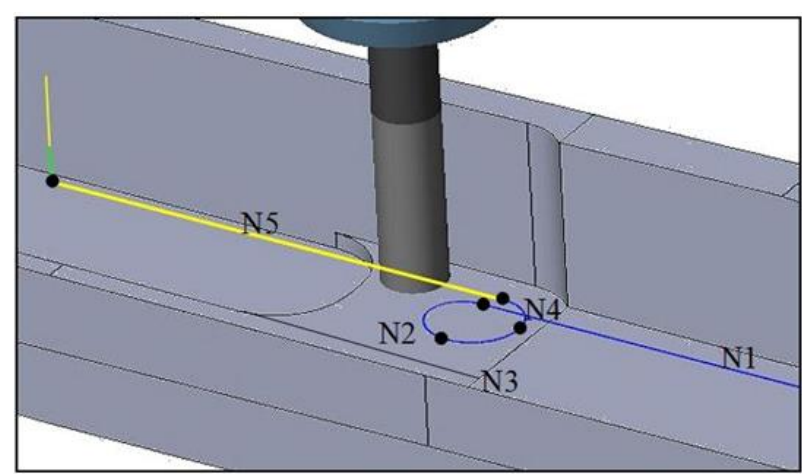

Figure 10: The machining path of the stringer section

The trajectory of the tool for the study area consists of five frames. Two linear frames N1, N5 are connected by three arcs of circles N2, N3, N4. The radius of curvature of the arc of the circle in frame $\mathrm{N} 4$ is determined by the magnitude of the radius of conjugation of the area in wall thickness variation, and the radius of the auxiliary frames N2, N3 are selected as possible taking into account the limitation of displacement space. For the entire treatment area, the feed rate is $5000 \mathrm{~mm} / \mathrm{min}$. At the end of the frame N5 is a complete stop of the tool.

In Fig. 11, shown the schedule of giving contour $F(t)$ variation fixed in CNC system is resulted [33] in the process of executing the control program on the upgraded machine FP7SMN2. The contour feed scheduling subsystem performed the formation of the contour feed variation plan, according to which the processing of frames N2, N3, N4, N5 is performed on the feed, which is less than specified in the control program.

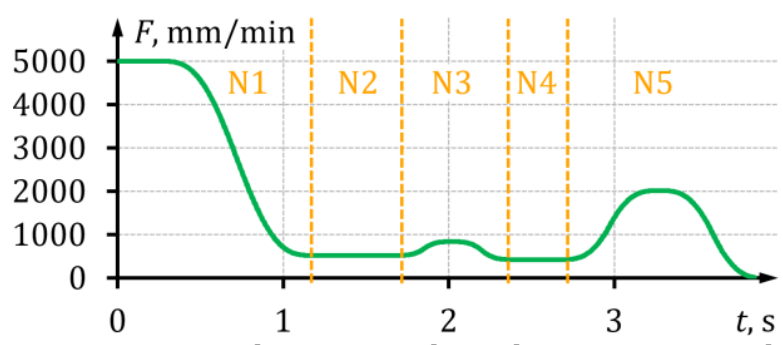

Figure 11: Feed variation along the processing path

The reduction of the feed in the frames N2, N4 is performed due to the limitation of the allowable jerk. In frame N3, the main limitation was the allowable acceleration, and in frame N5, the contour feed is 
limited under the condition of braking to a complete stop at the end of the frame.

The most important parameters of the machining mode, in addition to the cutting width $\left(a_{p}\right)$ and the thickness of the cut layer $\left(a_{e}\right)$, are the cutting speed $\left(V_{C}\right)$ and feed. When programming the milling in the CNC program, the minute feed $(F)$ and the spindle speed $(S)$ are set, but the characteristics of the cutting process are primarily determined by the feed rate $\left(f_{Z}\right)$

$$
f_{z}=\frac{F}{Z \cdot S} \text {. }
$$

The cutting speed is determined by the tool diameter $(D)$ and the spindle speed $(S)$

$$
V_{C}=\frac{\pi \cdot D \cdot S}{1000} \text {. }
$$

The high-speed machining process is best implemented while maintaining the constancy of the cutting parameters $\left(a_{p}, a_{e}, V_{C}, f_{Z}\right)$ on all sections of the trajectory. However, the use of Look-ahead algorithms leads to a violation of the specified technological modes in order to ensure the accuracy of the trajectory. In Fig. 12, b shown the variation of feed to the tooth along the processing trajectory. On the considered section of the trajectory at a constant cutting speed, the feed to the tooth changes by an order of magnitude.

According to expression (1) and the data given in [30] at 10-fold variation of giving on a tooth and accordingly weight of chip there is a 5 -fold variation of heat release in the course of cutting. Such a variation in the ratio of the cutting parameters leads to an increase in the temperature of the chips and can lead to a violation of the normal cutting process, for example, to the sticking of the workpiece material to the tool. To eliminate the probability of such a phenomenon, it is necessary to reduce the range of variation in the feed to the tooth due to the slowing of the feed on curved sections of the trajectory, but this is not always possible due to limited characteristics of servo drives. The cutting speed at a fixed machining trajectory is the only parameter in expression (1), the effect of which can provide a reduction in the amount of heat released during cutting in areas of deceleration of the contour feed.

Reducing the temperature of the cutting process due to deceleration of the tool movement along the machining path can be achieved by partially reducing the spindle speed according to the expression:

$$
S_{\text {adapt }}=S \cdot\left[1-\frac{K}{100} \cdot\left(1-\frac{F}{F_{\text {set }}}\right)\right]
$$

where $S_{\text {adapt }}$ is the spindle speed in the adaptive contour feed tracking mode; $S$ is spindle speed set in the CNC program; $K$ is the coefficient of allowable reduction of spindle speed at complete stop of the working bodies; $F$ is current feed on the trajectory of processing; $F_{\text {set }}$ is the feed specified in the CNC program.

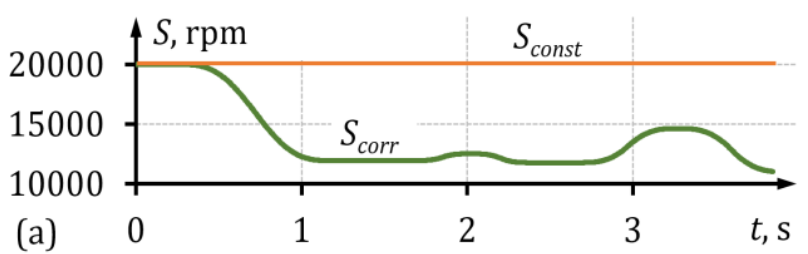

(a)

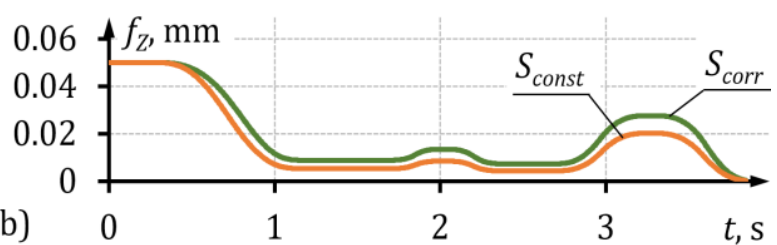

Figure 12: Variation of machining parameters:

(a) - variation of spindle speed along a trajectory;

(b) - variation of feed to the tooth along the trajectory

To coordinate the modes of operation of the spindle in the two-level CNC system [33] developed functions G786, G787, which ensure the maintenance of the allowable feed to the tooth while deceleration the contour feed.

For example, function G786 K30 activates the spindle speed adaptation mode with a spindle deceleration of up to $30 \%$ while reducing the contour feed to a complete stop. Function G787 cancels the cutting speed adaptation mode. The parameter $K$ is set as a percentage.

The proposed method of the spindle rotation speed adapting according to variation the contour feed takes into account the ratio of the dynamic characteristics of the spindle and auxiliary axes and ensures the normal operation of the cutting tool even with a complete stop of the auxiliary axes.

In Fig. 12 comparative diagrams of machining parameters variation on the considered area of a trajectory (Fig. 10) in a processing mode with a constant speed of cutting $\left(S_{\text {const }}\right)$ and a mode of adaptation of cutting speed $\left(S_{\text {corr }}\right)$ are present. When the feed is decelerated to 10 times in frames N2, N4 (Fig. 12, a), the spindle speed is reduced by $30 \%$ from $16,000 \mathrm{rpm}$ to $11,000 \mathrm{rpm}$. This variation in the spindle rotation speed leads to a slight variation in the feed to the tooth along the trajectory (Fig. 12, b) and a significant variation in the characteristics of the cutting process in the space of technological parameters (Fig. 13).

Fig. 13 combines a diagram of an unfavorable combination of cutting parameters and a diagram of changes in process parameters in the implementation of the proposed method of adapting the cutting speed.

It should be noted that the proposed method does not take into account the influence of vibrations arising from the machining of non-rigid (thinwalled) parts [34-36] and requires further development. 
In this example, to obtain a satisfactory result of machining a part from alloy 1933, it is sufficient to apply the spindle speed reduction factor $K=20 \%$.

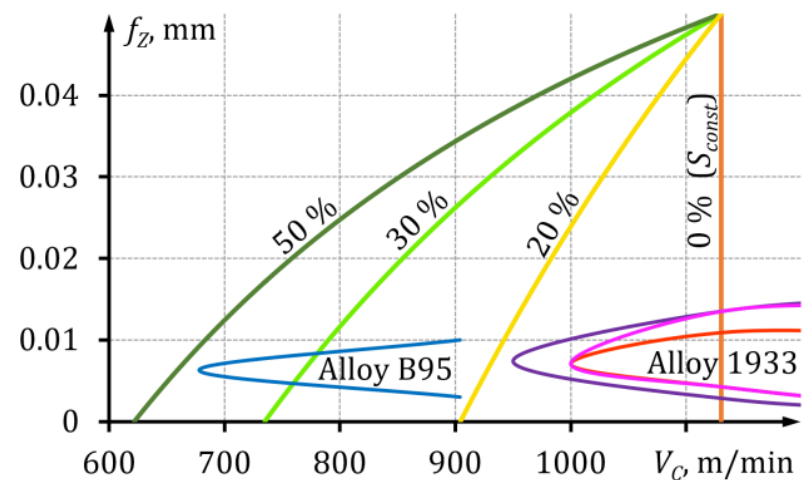

Figure 13: "Deviation" from the area of unfavorable combination of cutting parameters with adaptive control of the cutting speed by variation the contour feed

While in the manufacture of a similar part of the alloy B95 will require a reduction in speed up to $50 \%$. The proposed method is used in the modernization of long machine tools and is used in the manufacture of aircraft parts of the "Antonov" company airplanes.

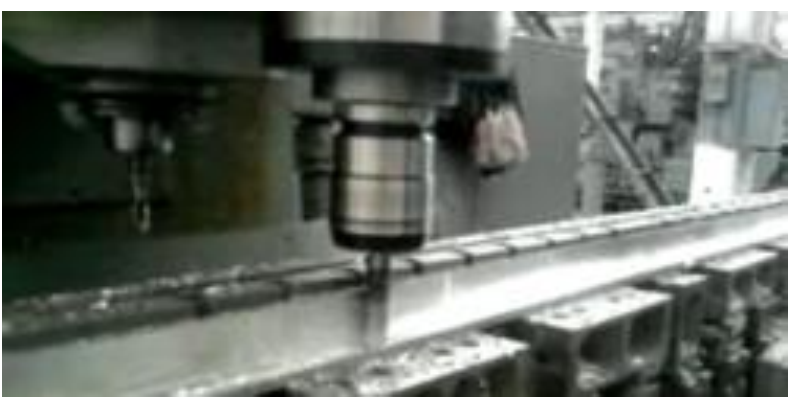

Figure 14: Manufacturing of a spar belt of the "Antonov" company airplanes

\section{Conclusions}

Experimental investigations of the high-speed machining of aluminum alloys limiting modes have shown that to ensure a stable cutting process without sticking the processed material to the tool, it is sufficient to carry out a slight decrease in the cutting speed with a significant (by an order of magnitude) decrease in the contour feed. This fact suggests that the dynamic characteristics of the auxiliary spindle axes and will be sufficient to provide coherent variation of contouring feed and speed.

To exclude sticking of the processed material to the tool with a significant feed deceleration in the curved areas of the processing path, it is sufficient to reduce the cutting speed by $20 \ldots 30 \%$, which provides a developed method for adapting the cutting speed by the feed variation.

\section{References}

[1] Chen, F., Lorenzo-Gómez, R., \& Asante, K.A. (2019). Integral forming of turbine drill impeller. International Journal of Mechatronics and Applied Mechanics, (6), 145-150.

[2] Matyska, V., Kolář, P., Sulitka, M., \& Fojtů, P. (2019). Optimization of five-axis finish milling using a virtualmachine tool. MM Science Journal, 2019(05), 3534-3543.

[3] Bernatskyi, A.V., Berdnikova, O.M., Klochkov, I.M., Sydorets, V.M., \& Chinakhov, D.A. (2019). Laser welding in different spatial positions of T-joints of austenitic steel. IOP Conference Series: Materials Science and Engineering, 582, 012048.

[4] Anghel, C., Gupta, K., \& Jen, T.C. (2020). Effect of laser beam cutting parameters on productivity and dimensional accuracy of miniature spur gears of stainless steel. IOP Conference Series: Materials Science and Engineering, 971, 022081.

[5] Plankovskyy, S., Tsegelnyk, Y., Shypul, O., Pankratov, A., \& Romanova, T. (2020). Cutting irregular objects from the rectangular metal sheet. In M. Nechyporuk, V. Pavlikov, D. Kritskiy (Eds.) Integrated Computer Technologies in Mechanical Engineering. AISC, vol. 1113 (pp. 150157). Springer.

[6] Grzesik, W. (2018). Hybrid additive and subtractive manufacturing processes and systems: A review. Journal of Machine Engineering, 18(4), 5-24.

[7] Plankovskyy, S., Shypul, O., Tsegelnyk, Y., Tryfonov, O., \& Golovin, I. (2016). Simulation of surface heating for arbitrary shape's moving bodies/sources by using R-functions. Acta Polytechnica, 56(6), 472-477.

[8] Zeng, Q., Luu, V.H., \& Saedudin, R.R. (2020). Motion control system of numerical control machine tool under image processing. International Journal of Mechatronics and Applied Mechanics, 2(8), 21-30.

[9] Kolar, P., Sulitka, M., Fojtû, P., Falta, J., \& Šindler, J. (2016). Cutting force modelling with a combined influence of tool wear and tool geometry. Manufacturing Technology, 16(3), 17-18.

[10] Jacso, A., Szalay, T., Jauregui, J.C., \& Resendiz, J.R. (2019). A discrete simulation-based algorithm for the technological investigation of $2.5 \mathrm{D}$ milling operations. Proceedings of the Institution of Mechanical Engineers, Part C: Journal of Mechanical Engineering Science, 233(1), 78-90.

[11] Kurin, M.O. (2020). Determination of the boundaries of plastic zone of metal deformation during the cutting. Progress in Physics of Metals, 21(2), 249-273.

[12] Vovk, A., Sölter, J., \& Karpuschewski, B. (2020). Finite element simulations of the material loads and residual stresses in milling utilizing the CEL method. Procedia CIRP, 87, 539-544. 
[13] Avevor, Y., Moufki, A., \& Nouari, M. (2016). A thermomechanical analysis of sticking-sliding zones at the tool-chip interface in dry high-speed machining of aluminium alloy A2024-T351: A hybrid Analytical-Fe model. AIP Conference Proceedings, 1769, 080008.

[14] Altintas, Y., \& Aslan, D. (2017). Integration of virtual and on-line machining process control and monitoring. CIRP Annals, 66(1), 349-352.

[15] Obukhov, A.I., Martinova, L.I., \& Lyubimov, A.B. (2020). Developing of the Look Ahead algorithm for linear and nonlinear laws of control of feedrate in CNC. Automation and Remote Control, 81(2), 380-386.

[16] Pliuhin, V., Korobka, V., Karyuk, A., Pan, M., \& Sukhonos, M. (2019). Using Azure Machine Learning Studio with python scripts for induction motors optimization web-deploy project. In 2019 IEEE International Scientific-Practical Conference Problems of Infocommunications, Science and Technology (PIC S\&T) (pp. 631-634). IEEE.

[17] Sokolov, V., Krol, O., Romanchenko, O., Kharlamov, Y., \& Baturin, Y. (2020). Mathematical model for dynamic characteristics of automatic electrohydraulic drive for technological equipment. Journal of Physics: Conference Series, 1553, 012013.

[18] Pliuhin, V., Sukhonos, M., \& Bileckiy, I. (2020). Object oriented mathematical modeling of electrical machines. In 2020 IEEE 4th International Conference on Intelligent Energy and Power Systems (IEPS) (pp. 267-272). IEEE.

[19] Landau, I.D., Lozano, R., M'Saad, M., \& Karimi, A. (2011). Adaptive control: algorithms, analysis and applications. Springer Science \& Business Media.

[20] Petrakov, Y., Danylchenko, M., \& Petryshyn, A. (2017). Programming spindle speed variation in turning. Eastern-European Journal of Enterprise Technologies, 2(1-85), 4-9.

[21] Zhang, J. (2018). Research on CNC lathe programming and improving machining accuracy. IOP Conference Series: Materials Science and Engineering, 452, 042050.

[22] Wang, C., Ghani, S.B., Cheng, K., \& Rakowski, R. (2013). Adaptive smart machining based on using constant cutting force and a smart cutting tool. Proceedings of the Institution of Mechanical Engineers, Part B: Journal of Engineering Manufacture, 227(2), 249-253.

[23] Rebelein, C., \& Zaeh, M.F. (2016). Friction in feed drives of machine tools: investigation, modeling and validation. Production Engineering, 10(4), 497-507.

[24] Martinova, L.I., \& Fokin, N.N. (2018). An approach to creation of a unified system of programming CNC machines in the dialog mode. MATEC Web of Conferences, 224, 01101.
[25] Martinova, L.I., \& Martinov, G.M. (2019). Prospects for CNC machine tools. Russian Engineering Research, 39(12), 1080-1083.

[26] Erkorkmaz, K., \& Altintas, Y. (2001). High speed CNC system design. Part I: jerk limited trajectory generation and quintic spline interpolation. International Journal of Machine Tools and Manufacture, 41(9), 1323-1345.

[27] Beudaert, X., Lavernhe, S., \& Tournier, C. (2012). Feedrate interpolation with axis jerk constraints on 5-axis NURBS and G1 tool path. International Journal of Machine Tools and Manufacture, 57, 7382.

[28] Kombarov, V., Sorokin, V., Fojtů, O., Aksonov, Y., \& Kryzhyvets, Y. (2019). S-curve algorithm of acceleration/deceleration with smoothly-limited jerk in high-speed equipment control tasks. $M M$ Science Journal, 2019(04), 3264-3270.

[29] Grzesik, W. (2020). Modelling of heat generation and transfer in metal cutting: A short review. Journal of Machine Engineering, 20(1), 24-33.

[30] Mazur, N.P., Vnukov, Y.N., Grabchenko, A.I., Dobroskok, V.L., Zaloha, W.A., Novoselov, Y.K., \& Yakubov, F.Y. (2013). Fundamentals of material cutting theory. National Technical University "Kharkiv Polytechnic Institute" (in Russian)

[31] Augustine, U., \& Olisaemeka, N. (2013). Thermal aspect of machining: evaluation of tool and chip temperature during machining process using numerical method. The International Journal of Engineering and Science (IJES), 2(4), 66-79.

[32] Grubiy, S.V., \& Zaitsev, A.M. (2013). Investigation of end mills for milling parts made of aluminum alloys. Science and Education, 12, 31-52. (in Russian)

[33] Aksonov, Y., Kombarov, V., Fojtů, O., Sorokin, V., \& Kryzhyvets, Y. (2019). Investigation of processes in high-speed equipment using CNC capabilities. MM Science Journal, 2019(04), 32713276.

[34] Plankovskyy, S., Myntiuk, V., Tsegelnyk, Y., Zadorozhniy, S., \& Kombarov, V. (2021). Analytical methods for determining the static and dynamic behavior of thin-walled structures during machining. In S. Shkarlet, A. Morozov, \& A. Palagin (Eds.), Mathematical Modeling and Simulation of Systems (MODS'2020). AISC, vol. 1265 (pp. 82-91). Springer.

[35] Kononenko, S., Dobrotvorskiy, S., Basova, Y., Gasanov, M., \& Dobrovolska, L. (2019). Deflections and frequency analysis in the milling of thin-walled parts with variable low stiffness. Acta Polytechnica, 59(3), 283-291.

[36] Jáuregui, J.C., Reséndiz, J.R., Thenozhi, S., Szalay, T., Jacsó, Á., \& Takács, M. (2018). Frequency and time-frequency analysis of cutting force and vibration signals for tool condition monitoring. IEEE Access, 6, 6400-6410. 